\title{
International Helgoland Symposium: Convener's report on the Informal Session on marine ecosystem research and man's dependence on the sea
}

\author{
J. W. HedgPeth \\ Santa Rosa, California, USA
}

\begin{abstract}
This report on an informal session held during the International Helgoland Symposium 1976, emphasizes basic perspectives of marine-ecosystem research and man's dependence on the sea. Particular reference is made regarding the difficulties to predict manmade changes in the marine environment.
\end{abstract}

The idea of the discussion was to arrive at some consensus about the research and data requirements needed to study the general situation in nature, or the ecosystem. In view of the many things said by speakers during the previous days of the Symposium, especially at the panel discussion about management of the North Sea, it is not surprising that matters got off to a slow start. The real difficulty, however, stems from the nature of our concept of the ecosystem and what information may be significant in view of the obvious impossibility of attempting to gather data on all possible variables, species, life cycles, and so on. Our concern is to understand the natural system well enough to predict changes and effects from what data we can gather, and to provide information that will justify decisions affecting the environment. In this context the time scale of events in nature is irreconcilable with the political need for a quick fix. With such considerations constantly in mind it was difficult to consider precise methodologies or "cook book" procedures, to the obvious distress of one indignant commentator who had hoped, apparently, for such information. Further, it was not possible even to approach the politico-legal question: how can it be proved before a court that a given pollutant or action will have an effect on an ecosystem?

With respect to the "nature of the ecosystem", which must govern whatever we do to study it, we are very much like the several blind men who encountered the elephant (a most unlikely animal, when one thinks about it), although we have, we hope, the advantage of knowing our experience or vision is incomplete. But we did not have time to compare or reconcile our impressions because some participants were obliged to leave. Subsequent experience by the convener with deliberations of a committee of the California Water Quality Control Board on the research needs to detect the effect of effluents in San Francisco Bay suggest that agreement would have been impossible in an afternoon in any event.

All the matters discussed at the International Helgoland Symposium have come 
up during these protracted conferences on how to study San Francisco Bay. Data must be obtained to apply in some elaborate, almost mythical model but no one can be sure which data may be more significant, so some factions would have everything possible observed and measured. The idea of index organisms has received much notice, including Mytilus edulis. The problem of base-line studies that may miss significant natural variation in time and space, as discussed by Joseph Connell, have been very much in mind. San Francisco Bay is, at present, suffering a combined natural and manmade catastrophe: drought and diversion, but the base line is inadequate, in such a complex ecosystem, to provide useful information. There has been consideration of some such central data scheme for information at the species level, as proposed by Evan Evans and our Environmental Protection Agency (E.P.A.). We do have a central depository and record plan, administered through the California Academy of Sciences. This has been made necessary because of the large number of non-native species that have found their way into the San Francisco Bay system. Some simplified in-situ experiments have been advocated, but have not been too enthusiastically received; many of us share the distrust of W. P. Davis of the E.P.A., who remarked at another session of the symposium that only the foolhardy become involved with ecosystem experiments. However, one matter not discussed adequately at Helgoland is the urge of the engineers among us for some sort of number. This arouses the distrust of thoughtful naturalists, who also see many problems with carrying the organisms into the laboratory, although many physiologists and other experimentally minded persons can trust only the data of their experiments in controlled conditions. But this is not studying the natural system, only its excised parts.

Thus the ecosystem sea-elephant is either a matter of knowing the chemicals, or the species, crammed into a computer or enumerated in the field, a model of everything, or the reaction of a single species to various natural and man-induced perturbations, or counting and weighing all organisms from (and in) the bottom retained by a screen of some stated mesh size, or the variations of phytoplankton and zooplankton, or perhaps simply some sort of productivity index. Perhaps the most significant events are those taking place at the world's interfaces, of gas exchange and microbial activity involving, as $\mathrm{E}$. P. Odum said at a recent Wetlands conference, the global cycle of three common elements, of nitrogen, sulfur and carbon (and oxygen, of cource) in the form of nitrate and ammonia, $\mathrm{H}_{2} \mathrm{~S}$ and sulfate, and methane. This would mean that one of our blind men would have to be able to smell, or perhaps draw his inference on the basis of what has been left behind by the elephant.

The analogy of the blind men and the elephant is perhaps not quite fair. Our problem is not that we are blind but that none of us can see everything at once and we all suffer from some impairment or bias of vision, so no one is sure just what the elephant looks like, especially a sea-elephant. In such a situation, it is only prudent to investigate this enigmatic animal, the ecosystem, by as many means and approaches as possible, that is, as time and money and skill permit. It is something like ordering the seafood platter at the restaurant because we are not sure what is best to eat, and it is less expensive than the whole lobster, with less risk of disappointment.

Author's address: Dr. J. W. Hedgpeth

5660 Montecito Avenue, Santa Rosa, California 95404, USA 